Monatsschrift f. Geburtshülfe u. Gynäkologie 1915;42:81-82

\title{
Feldgraue Geburtshülfe 1914/15
}

Ebenso wie im Krieg 1870/71 zögern deutsehe Ärzte in Feindesland nicht, dessen Einwohnern ihre Kunst und Wissenschaft dienstbar zu machen, wo diese ihrer Hülfe bedürfen. Jetzt wie damals sind die Ärzte der besetzten Landesteile selbst in den Heeresdienst ihres Vaterlandes eingetreten, wenn sie nicht vor dem eindringenden Feinde flohen. Das letztere hat Ref. in dem lothringischen Dorf erfahren, in dem er an einem Kriegslazarett des VII.Korps während der Belagerung von Metz betätigt war. Ein Zufall hatte ihn mit der Schulschwester in Berührung gebracht. Diese hatte nach Abzug der beiden Ärzte des großen und reichen Dorfes die Pflege der Ortskranken übernommen. Ruhr und Typhus neben den der Jahreszeit entsprechenden Erkrankungen verursachten ernsteSorgen. Unsere Lazarettarbeit war nicht gering, so hatten wir zu 2 eine Nacht um die andere Wache in unseren Baracken. Immerhin blieb mir Zeit, den Pfleglingen der Schwester, besonders in den dienstfreien Näch-ten,meineärztliche Aufmerksamkeit zu widmen. Insbesondereerforderte eine Zeitlang meine Sorge die Ortshebamme. Schwer ruhrkrank kämpfte sie in ihren Phantasien mit der Hebamme des Nachbar dorfes, deren Eindringen in ihre Praxis sie befürchtete. Es gereichte ihr zu großer Beruhigung, daß ich 11 ihrer Klientinnen im Dorf den entsprechenden Beistand bei der Niederkunft leistete vom Clysma bis zum Kinder -baden. Die Dankbarkeit der Bevòlkerung war überaus herzlich. Sie Monatsschrilt f. Geburtshülfe u. Gynäkologie. Bd. XLII. Heft 1.6

$*$ - >

Eugen Köberlé $\uparrow$.

fand neben der Anerkennung des Ortsgeistlichen in seinen Gebeten ihren materiellen Ausdruck in den Erstlingsfrüchten des Gartens und des Hühnerhofes. Restez chez nous, docteur! vous serez Tange de ce pauvre petit pays!

Mir ist seitdem nicht mehr das Glück beschieden worden, allgemeine Praxis zu treiben.

Eine besondere Gelegenheit zu ärztlicher Betätigung bietet sich naturgemäß da. wo in kleinen Orten in Belgien der vielmonatliche Auf-

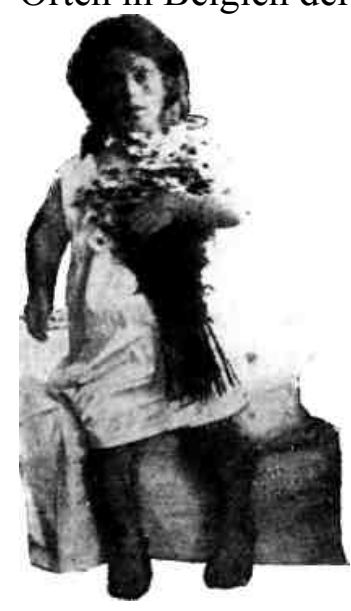


enthalt unserer Ärzte unvermeidlich eine kollegiale Berührung mit den Eingesessenen herbeigeführt hat. Das zeigt eine Erfahrung, welche unser Kollege $Æ^{5} / 8$ er\&e-Bochum berichtet. Er stand als Oberstabsarzt mit einem Landsturmbataillon in Chimay. Der dortige Geburtshelfer rief seine Hülfe an bei der Entbindung einer 39 jähr. Ipara-Troddel mitsehr unliebenswürdigenKraftäußerungen. $107 \mathrm{~cm}$ groß. Conj. diag. 4, 9, Conj. vera 4. 4. Der hinzugerufene Arzt wendet das Kind, extrahiert es bis auf den Kopf, den er nicht zu entwickeln vermag. Everke machte nach seiner uns alien wohlbekannten Art den konservativen Kaiserschnitt. E. amputierte den Kindskopf, so daß der Rumpf nun durch die Scheide entwickelt werden konnte. Entfernung der Plaz. $-\lambda 7 / 8$ rschluß. - Ungestörte Genesung. Das beistehende Bild zeigt die Zwergin im Stolz über ihre Errettung. - A. Martin.

Eugen Köberlé †.

16. Juni 1915.

Mit E. Köberlé ist einer der wenigen noch unter uns weilenden Zeugen der frühesten Kindheit der operativen Gynäkologie dahin-gegangen! Verhältnismäßig früh hatte er sich vom Schauplatz seiner welterobernden Arbeit zurückgezogen: nur vereinzelte unter uns haben ihn noch auf der Höhe seines Wirkens gesehen, nur wenige ihn über-haupt persönlich kennen gelernt! In Schlettstadt am 4. Januar 1828 geboren, ist er seiner Elsässer Heimat unentwegt treu geblieben. Nachdem er in jungen Jahren sich mit Eifer der Mathematik, Physik und Chemie befleißigt, kunstgewerb-lichen Neigungen hingegeben, dann Juristerei getrieben, auch an den politischen Bewegungen (1848-51) teilgenommen, wandte er sich der Medizin zu. $1853 \mathrm{im}$ Zeitraum eines Jahres erwarb er sich den Doktorhut mit einer Dissertation: ,,Beobachtungen über einige Punkte der patho-logischen Anatomic" zu erwerben, 2 Monate später sich mit einer Arbeit ,,Über die Ulzeration im allgemeinen und im speziellen der verse hie-dener Ge we be'"an der damals mit vortreff lichen Lehrern besetzten medizinischen Fakultät in Straßburg zu habilitieren. Stoltz vertrat dort die großen Traditionen der Geburtshülfe, Sedülox die der Chirurgie 